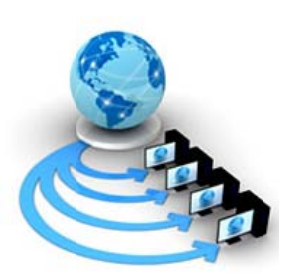

Volume 9, No. 1, January-February 2018

International Journal of Advanced Research in Computer Science

REVEW ARTICLE

Available Online at www.ijarcs.info

\title{
INTERNET OF THINGS (IOT) ARCHITECTURE, CHALLENGES, APPLICATIONS: A REVIEW
}

\author{
Komal Middha \\ ME (IT), U.I.E.T, Panjab University \\ Chandigarh, India
}

\author{
Dr. Amandeep Verma \\ Assistant Professor, U.I.E.T, Panjab University \\ Chandigarh, India
}

\begin{abstract}
Internet of Things (IoT) is one of the latest as well as the most attractive field for researchers. It is defined as a network of physical devices having sensing and network capabilities that enables the devices to store and exchange data. It is considered to be a bridge between various technologies. It extends its connectivity from physical devices such as laptops, tablets to the real life things. It is not only confined to a restricted area but it has expanded its roots in almost all fields such as in business, education, industry, health etc. and find numerous of applications in these fields. This paper basically gives an overview of what IoT is, along with its architecture, applications, technology background, various challenges and its future prospect.
\end{abstract}

Keywords: IoT; RFID; WSN; Wifi; WiMax

\section{INRODUCTION}

IoT- One of the remarkable development in the global industry for exchanging information as well as for communication between devices having sensing capabilities. Earlier very few devices were connected to each other but with rapid growth of internet, enormous of devices get connected either through wire or any wireless media. This lead to idea of connecting objects to internet, termed as Internet of Things (IoT)[1]. The term IoT was coined by Kevin Ashton in 1999[2]. Specialists had defined IoT with different perspective and there is no particular definition for it. The technical definition is that it is a network of physical objects accessed through internet [3]. These objects must have sensing capabilities. Another definition is- it is an open and wide range network of intelligent objects that that can share information, data and resources. The exchange of information takes place with the help of Wireless Sensor Networks (WSN) and Radio Frequency Identification (RFID) [4].IoT allows us to connect anything, anytime and from any place using any network communication [5]. The Fig. 1 shows the dimensions of IoT [6].

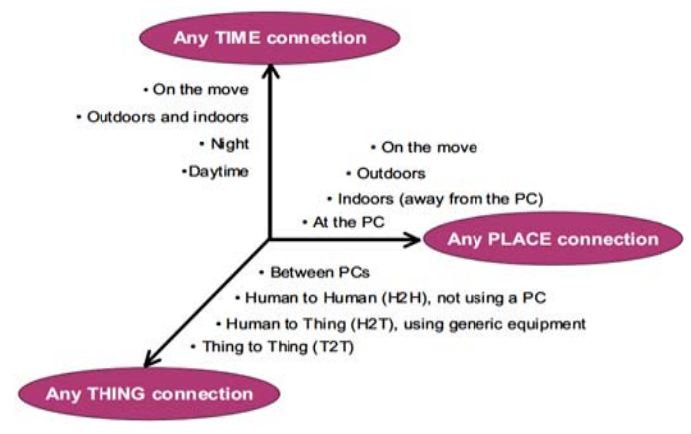

Figure 1. IoT Dimensions [6]

IoT is growing with a rapid rate and expanding itself in all domains either vertically or horizontally. Earlier it was used mainly in industry applications such as in production etc. But now it has expanded its roots in human life as weand has made it smart with numerous of smart applications. We can see from Fig. 2, how fastly it is evolving. In 2003 connected devices were 500 million and till 2015 it increases to 25 billion. According to researchers, by 2020 the number will increase to 50 billion.

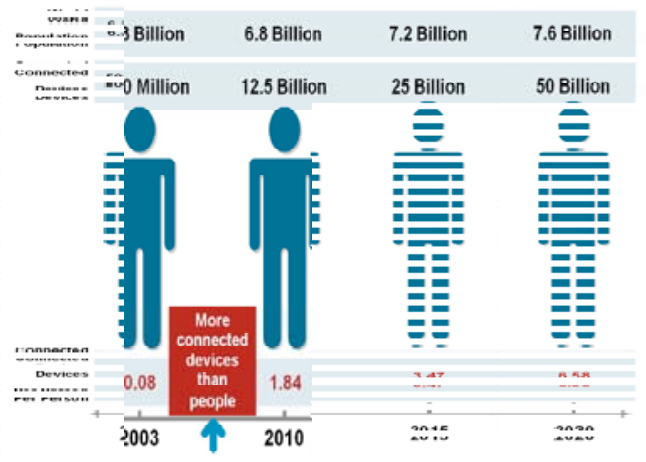

Figure 2. Status of IoT [7]

This paper gives an overview of IoT and also describes its various challenges and applications. The rest of the paper is divided into discrete sections. Section 2 defines its architecture. Section 3 discusses about its technologies. Section 4 and 5 describes applications and challenges respectively. The last section 6 concludes the whole paper.

\section{ARCHITECTURE}

An architecture defines the components of a system, how they work together and how data is exchanged between them. Different architectures has been defined for IoT. Some of them are listed below. 


\section{A. IoT Forum Architecture[8]}

According to this, IoT architecture is divided into three layers namely Perception, Network and Application layer, shown in Fig. 3.

Each layer has its own functionality. Perception layer is responsible for identifying smart objects in the environment. Network layer as the name indicates is used for routing and processing of data. And the application layer is used for providing services to the users through various applications.

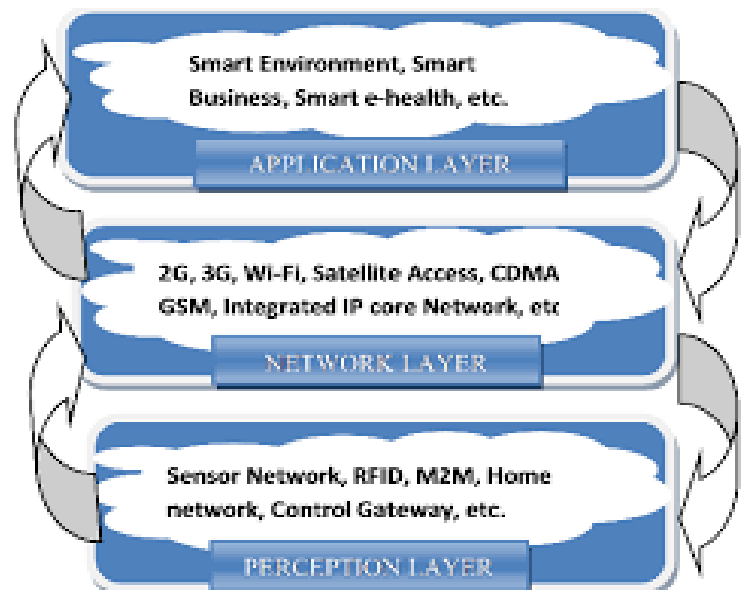

Figure 3. IoT Forum Architecture [8]

Be that as it may, a portion of the scientists feel that IoT comprises of four layers of design. The fourth layer is viewed as a help layer. Technologies utilized as a part of this new layer are distributed computing, Fog computing and so forth. It lie between the discernment and system layer of IoT customary design [9].

\section{B. ITU Architecture}

According to ITU [8], the IoT architecture is divided into five layers:

- Sensing layer

- Access layer

- Network layer

- Middleware layer

- Application layer

To further enhance security aspect, new six layer architecture was proposed [10]. It has hierarchical structure as shown in Fig. 4 and is described below:

- Coding layer: It is the topmost layer of IoT architecture. In this layer, a unique ID is allotted to each object [11], which helps in identifying each object uniquely.

- Perception layer: It is also known as physical layer. It consists of data and network sensors [12], which would sense various attributes of objects. It collects useful data about the object and converts it into digital signals [13]. These signals act as input for network layer.

- Network layer: The output of the perception layer becomes the input for the network layer and it is further transmitted to the middle layer via various transmission media, like WiMax,WiFi [14].
- Middle layer: It is used for processing the information that is received from various sensor devices [15]. After processing further actions are taken based on the results.

- Application layer: It allows user to access various applications IoT provide. IoT found its applications in vast areas like health care, transportation, government, retail etc [16].

- Business layer: It is also known as management layer, as it manages all the applications and services of IoT.

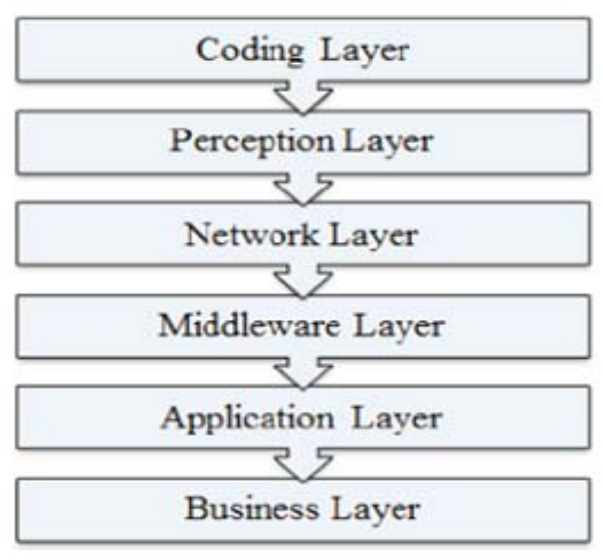

Figure 4. IoT Six Layer Architecture [10]

\section{IoT TECHNOLOGIES}

IoT consist of multiple connected "smart" devices which includes various technologies in them. The technologies included in IoT are Radio Frequency Identification (RFID), the sensor technology, nano technology and intelligent embedded technology [8]. The RFID form the backbone of IoT[16]. Instead of these traditional technologies, it supports many new upcoming technologies such as, remote communication technology, remote information transmission technology [17].

- Radio Frequency Identification (RFID): It refers to small device having a small chip and an antenna. It is used to identify an object using radio waves [18]. It consists of readers and tags which identify objects and generates appropriate signals [19]. These signals are further transmitted to readers using RFID frequency and are analyzed by the processors. The Fig. 5 below shows the RFID scenario.

- Wireless Sensor Network (WSN): Wireless Sensor Network consists of independent devices having sensing capabilities that monitors physical or environmental conditions, such as temperature, pressure. It consists of two main components - sensor nodes and base station as shown in Fig. 6. It consists of numerous amount of sensor nodes and the nodes communicate with each other using radio signals. Data is passed from one node to another [20] and a base station act as an interface between users and the network [21]. 


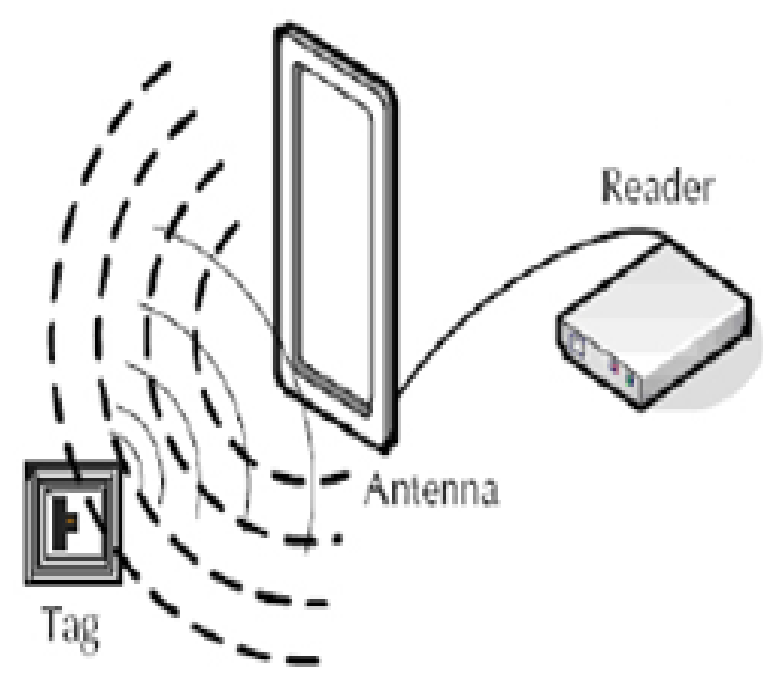

Figure 5. RFID [18]

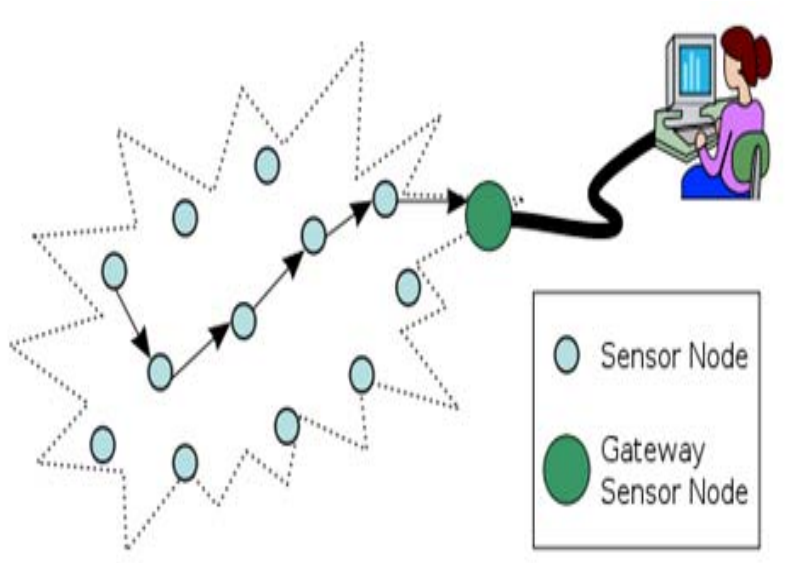

Wireless sensor network

Figure 6. WSN [20]

- Cloud Computing: Cloud computing simply provides resources and data to computers. It is on- demand process and one of the important technology of IoT. As IoT generates data, cloud computing provides a path to the data to travel to its destination [22].

- Wireless Fidelity (Wi-Fi): It forms the basis for the IoT . There are millions of devices that are accessing $\mathrm{WiFi}$ services and it is based on IEEE 802.11 standard. The integration of Wi-Fi into handheld devices has increased its demand and nowadays entire cities are becoming WiFi corridors [8].

- ZigBee: It was developed by ZigBee Alliance in 2001 and based on IEEE 802.15.4 standard. This IEEE standard was further revised in year 2006 and 2011 with 15.4e and 15.4g [20]. The main characteristics are low cost, reliability, flexibility and found applications in wide areas.

\section{IoT APPLICATIONS}

IoT being a "smart system" found application in many domains. Some of them are listed below:

- $\quad$ Smart Home: IoT found its application in smart home, as it is improving the living standard with home automation. We can control various systems according to our requirements such as lighting system, water supply etc. and it helps in saving resources as well.

- Smart Environment: Smart environment is that where everything comprises of "smart system" such as smart government, smart utilities, smart buildings [23]. With the help of this we can monitor traffic in city, pollution level, waste management and also with modern technologies of IoT we can predict natural disasters as well such as earthquake, landslide etc.

- Smart City: A smart city aims to provide IoT solutions so that it becomes easy to manage city assest. The goal is to improve traffic control system, education system, transportation system, hospitals system and many more to make a city a smart city.

- Hospitals: The IoT found its application in health care also. It aims to improve the hospital service by adding smart features like some hospital has "smart bed", that will detect when the bed is reserved and when it will be free.

- $\quad$ Shopping: It found its application in shopping also. While shopping in a market, the goods will automatically introduce about them and when you buy a good it will give indication to staff to put a new one there. So in this way it is making shopping scenario so smart.

- Agriculture: IoT in agriculture field help in improving the production rate of crops. It helps in monitoring the soil texture, nutrients, quality, humidity of soil, so that it can help in detecting which area is suitable for particular crop [24].

- $\quad$ Shrewd and Safe Mining: Mining security is of huge worry in different nations. Be that as it may, IoT can be sent to guarantee safe and mishap free mining. WiFi, RFID labels sent in mining regions has the ability of sending a notice flag. Additionally, mining organizations in threat circumstances can track the area of diggers and can find or direct them likewise [25].

\section{A. IoT-Future Applications}

Nowadays, technology is expanding at a fast rate and everyone either directly or indirectly accessing these technologies. Just like Internet has expanded in the whole world, in the same way IoT is going to expand. It will be just like new internet. As IoT found its application in various fields, one can predict that the future of IoT is going to very bright. It will surely come up with unexpected developments that are beyond one's imagination and with these developments it will make our life easy than easier.

Some of the future predictions about IoT are [26]:

- Information: One will be able to access information at a very fast rate, which means that the query of user will get solved just by thinking of it. It will save a lot of time as well. 
- $\quad$ Monitoring: IoT being a SMART technology i.e. Self Monitoring And Reporting Technology, will help to monitor various scenarios. For example: while sitting in an office, one can get to know what is happening at home.

- Food Production: It will help in developing many new technologies in food production such as pre planned analysis of plants and crops can be done. In advance we get to know what are the requirements of the plants and crops such as water requirement, fertilizer etc.

So, in future IoT is going to revolutionize the whole world. Recently we are using many applications of IoT and there are many more to come.

\section{IoT CHALLENGES}

As IoT has come up with many new opportunities and applications in various fields, but it faces some challenges as well. Some of them are:

- Security: Security is one of the biggest challenges in IoT. As the IoT devices such as sensors, acutators and they are directly accessible, so they are prone to various security attacks such as spoofing, denial of service, altering attack[27]. So there is need to deploy against these attacks.

- Data Storage: As the amount of data is increasing with a very high pace, so the storage of data becomes a major problem. Data storage also effects data protection. As the stored data crash, it is difficult to backup all the stored data. So it is also major problem in IoT.

- Standard and interoperability challenge: Set of standard has a huge impact on IoT. Each sort of objects in Internet of Things have diverse data, preparing and correspondence abilities. Diverse objects would likewise be subjected to various conditions, for example, the vitality accessibility and the correspondences data transfer capacity necessities. To encourage correspondence and participation of these items, basic benchmarks are required [5].

- Architecture challenge: IoT consist of couple of devices connected, sensors and many more. Different device uses different set of protocols and standards to communicate. And there is no well defined standard and rules for communication, so it becomes a major problem in IoT.

- Privacy: It is one of the other challenges to IoT. As it comprises of number of devices connected and allows anyone to access anything from any place. But with this feature it affects the privacy of sensitive data. So some norms or rules must be set to avoid the violation of privacy.

\section{CONCLUSION}

In this paper we had examined what IoT is, how fast it is evolving, its architecture, technologies, applications, various challenges it faces and its future prospect. So in nutshell we can conclude that the whole future of global information depends on IoT and it will bring inevitable changes in technology. It will going to be a boon for many upcoming technologies.

\section{REFERENCES}

[1] C.Perera., C.H.Liu, S. Jayawar, "The emerging IoT marketplace from an individual perspective: a survey," in IEEE trans. on emerging topics in comp. ,vol. 3, issue 4, pp. 585-598, Jan2015. (Article in journal)

[2] J. Gubbi, R. Buyya, S. Marusic, M. Palaniswami, “ Internet of Things (IoT): A vision, architectural elements, and future directions," article in Future Gen. Comp. Sys., Elsevier, vol 29, issue 7, pp. 1645-1660, 2013. (Article in journal)

[3] S.Madakam, "Internet of things: smart things," in IJFCC, vol.4, no. 4, pp. 250-253,2015, doi:10.7763/IJFCC.2015.V4.395. (Article in journal)

[4] S. Madakan, R. Ramaswamy, S. Tripathi, "Internet of Things (IoT): A literature review," in Journal of Computer and Comm., vol 3,no. 5,pp. 164-173, 2015. (Article in journal)

[5] Z.K.A. Mohammad, E.S.A. Ahmed, "Internet of things applications, challenges and related future technologies," in World Scientific News, pp. 126-148, 2017.

[6] www.itu/int/internetofthings/on

[7] https://www.slideshare.net/MohanKumarG/internetofthingiot-aseminar-ppt-by-mohankumarg

[8] A.Khalid, "Internet of things architecture and research agenda," in IJCSMC, vol.5, issue 3, pp. 351-356, March2016. (Article in journal)

[9] M. Bilal, "A review of IoT architecture, technologies and analysis smartphone- based attacks against 3D printers”, pp. 1-21, 2017.

[10] R. T.Guthikonda, S. S.Chitta, S. Tekawade, T. Attavar, "A.comparitive analysis of IoT Architecture," in $8^{\text {th }}$ IEEE conference ,pp. 678-683, 2015. . (Article in a conference proceedings)

[11] Xu Chang, M. Zhang, F. Sui, "Architecture of internet of things and its key technology integration based on RFID," $5^{\text {th }}$ Int. Sympo. on Comp. Intell. and Design, vol 1, pp. 294-297, 2012. . (Article in a conference proceedings)

[12] D. Bandyopadhya, J. Sen, "IoT- applications and challenges in Technology and standardization," in Wireless Personal Communication, vol 58, issue 1, pp. 49-68, May 2011. (Article in journal)

[13] M.U.Farooq, M. Wasen, S. Mazhar, A. Khairi, T. Kamal , "A review on Interne of things(IoT)," in IJCA, vol 113, no.1, pp. 1-7, 2015. (Article in journal)

[14] Y. Zang, "Technology framework of the internet of things and its applications," in Electrical and Control Engg. (ICECE), pp. 4109-4112, 2011. (Article in journal)

[15] G.Shen., B. Liu, "The visions, technologies, applications and security issues of IoT” in Business and E-Govt. (ICEE), pp .1-4, May 2011. (Article in journal)

[16] Soumyalatha, S. G. Hedge, "Study of IoT- understanding IoT architecture, applications, issues and challenge," in IJANA, pp. 477-482, 2016. (Article in a conference proceedings)

[17] Shao, W. and Li, L, "Analysis of the Development Route of IoT in China," in China Science and Technology Information, vol 24, pp. 330-331, 2009. (Article in journal)

[18] C. Sun, "Application of RIFID technology for logistics on internet of things,” Elseiver, vol 1,pp. 106-111,2012. (Article in journal)

[19] H.Zhang,L.Zhu, "IoT: key technologies, architecture and challenges problems," in Computer Science andEngineering(CSAE), vol 4, pp. 507-512, 2011. (Article in journal) 
[20] Y.Pundir, N. Sharma, Dr.Y. Singh, "Internet of Things (IoT): challenges and future directive," in IJARCEE, vol 5, issue 3, March 2016. (Article in journal)

[21] MA.Matin and M.M Islam, "Overview of WSN," http://dx.doi.org/10.5772/49376, 2012.

[22] A. Meola, "The role of cloud computing and fog computing in Internet of Things revolutions,” 20Dec2016.

[23] S.Rajguru,S.Kenhekar and S.Pati, "Analysis of IoT in a small environment ," in IJANA, vol .4, issue 4, 2015. (Article in journal)

[24] F.Tongke, "Smart agriculture based on cloud computing and IoT,” in JCIT, vol8, no.2, Jan2013.(Article in journal)
[25] J.Kaur, K.Kaur, "A review on technologies, architecture, challenges, applications, future trends," in IJCNIS, vol. 9, pp. 57-78, 2017. (Article in journal)

[26] F. Khan, "Future scope and possibilities in internet of things," in Int. Conf. on Advances in Engg. Science and Mgt., Agra, pp. 310-313, 08 Nov 2015. (Article in a conference proceedings)

[27] M. Nawir, A. Amir, N. Yaakob, O. B. Lynn, "Internet of Things(IoT): taxonomy of security attacks," in ${ }^{3 r d}$ Int. Conf. on Electronic Design (ICED), pp. 321-326, 2016. (Article in a conference proceedings) 